\title{
Regulação do trabalho no contexto das novas relações público versus privado na saúde
}

\author{
Work regulation in the context of new public versus private \\ relations in health
}

Nelson Bezerra Barbosa ${ }^{1}$

${ }^{1}$ Secretaria deEstado da Saúde deGoiás. RuaSC $1 /$ 299, Parque Santa Cruz. 74860-270 Goiânia GO. nelsonbbarbosa@gmail.com
Abstract This work discusses the management of the work relations in the context of the new systems of public vs. private relation in health, having as reference the experience of the habilitation of Social Organizations ( $\mathrm{SO}$ ), responsible for the administration of a group of hospitals in the state of São Paulo. The urgency in this kind of management supported on the legal figure of the SO has implications in the management of $\mathrm{Human} \mathrm{Re}$ sources in $\mathrm{H}$ ealth $(\mathrm{HRH})$ through the adoption of flexibilization mechanisms which include ways of selection, hiring and dismissal, payment rules and functional progression similar to theactionsadopted by the market. The establishment of this sort of administration refers to the new paradigm proposed by the managerial administrative reform which suggests the exhaustion of the bureaucratic model to promote adjustment of the public administration to the transformations originated in the new stage of internationalization of the economy and its unfolding in the work world, as well as to the new standards of requirements of performance of the public field. Aspects related to the management of HHR are approached in the two ruling modalities in the Secretaria de Estado da Saúde de São Paulo: Direct Administration Hospitals (DAH) and units organized under the SO model $(\mathrm{SOH})$.

Key words Public-private in the health sector, $\mathrm{H}$ ealth human resources, $\mathrm{H}$ ealth social organizations
Resumo Este trabalho discute a gestão das relações de trabalho no contexto das novas formas de relação público/privado no setor saúde, toma como referência a experiência de habilitação de organizações sociais (OS), responsáveis pelo gerenciamento de um conjunto de unidades hospitalares no Estado de São Paulo. A emergência desta modalidade de gestão apoiada nesta figura jurídica (OS) tem implicações sobre a gestão de recursos humanosem saúde (RHS), por meio da adoção de mecanismos de flexibilização deste processo, que inclui formas de sel eção, contratação e descontratação, formas de remuneração e deprogressão funcional mais próximas das práticas adotadas pelo mercado. Esta modalidadedegestão remeteao novo paradigma proposto pela reforma administrativa gerencial, quesugere o esgotamento do model o burocrático para promover adequação da administração pública às transformações decorrentes da nova etapa de internacionalização da economia e seus desdobramentos do mundo do trabalho, bem como aos novos padrões de exi gência de desempenho do setor público. Aspectos relativos à gestão de RHS são abordados dentro de uma abordagem comparativa entreas duasmodalidades prevalentes na Secretaria de Estado da Saúde de São Paulo (SES-SP), com hospitais da administração direta (HAD) ehospitais sob a modalidade OS (H OSS). Palavras-chave Público-privado em saúde, Recursos humanos em saúde, Organizações sociais desaúde 


\section{Introdução}

As estratégias orientadas para busca de maior eficiência, por intermédio da descentralização, têm antecedentes históricos nos processos de reformas administrativas implementadas no Brasil. A reforma de 1967, com base no Decreto-lei $n^{\circ} 200$, introduziu a administração indireta com a criação de serviços autárquicos eintrodução de novas formas de contratação de pessoal. A despeito da excessiva centralização política, a inovação introduzida é a perspectiva descentralizante que a criação das autarquias ensejava.

Estas organizações recebiam tratamento diferenciado, podendo contratar a compra de bens e serviços sem a imposição das rígidas regras adotadas para a administração direta, situação que foi modificada com a Constituição de 1988, que submeteu as fundações e autarquias às re gras da administração direta ${ }^{1,2}$.

A reforma administrativa gerencial (1995), por meio do Plano Diretor da Reforma do Aparelho do Estado (PDRAE), propôs a publicização de serviços públicos nas áreas de educação, saúde, meio ambiente e pesquisa científica, com a descentralização da gerência destes serviços para entes públicos não-estatais. 0 objetivo é 0 de conferir maior autonomia administrativa a estes serviços, com maior agilidade para prover a contratação de bens e serviços, bem como de recursos humanos, para atender a necessidade de produção destas unidades, instituindo para estefim, a criação da figura jurídica denominada organização social ${ }^{3}$.

De acordo com o PDRAE, Organizações Sociais (O.S.) são entidades de interesse e de utilidade pública, associação sem fins lucrativos, surgidas da qualificação de pessoas jurídicas de direito privado, nas atividades de ensino, pesquisa tecnológica, desenvolvimento tecnológico, proteção e preservação do meio-ambiente 4 .

O Estado de São Paulo conta, hoje, com cerca de dezenove unidades hospitalares operando sob a modalidade de $0 \mathrm{~S}$, responsáveis pel o gerenciamento de quase quatro mil leitos. Estenovo modelo adota formas de gestão das relações de trabaIho dentro de uma lógica mais próxima da de mercado. Caracteriza-se, portanto, pelaflexibilização de formas seleção, contratação, remuneração e de progressão funcional. Ainda que sob intenso questionamento de suas bases legais, estemodelo vem se expandindo no país, obrigando técnicos, gestores e usuários a uma profunda reflexão sobre os limites entre público e privado no setor saúde, incluindo as vantagens e desvantagens so- bre o processo de flexibilização da gestão do trabalho e os riscos da precarização de vínculos, já observados na Estratégia de Saúde da Família.

Este trabalho se propõe a discutir aspectos relacionados à gestão das relações de trabalho, tomando como referência as práticas adotadas em duas unidades hospitalares da Secretaria de Estado da Saúde de São Paulo (SES-SP), representando os dois modelos prevalentes adotados pela instituição: hospitais da administração direta (HAD) e hospitais gerenciados por organizações sociais de saúde(H OSS). Discute os principais aspectos da gestão de Recursos H umanos em Saúde (RHS) em cada caso e suas implicações sobre o processo de regulação da formação da força de trabalho para o sistema, da prática profissional e do acesso, remuneração e progressão dentro do sistema.

No âmbito do presente trabalho, admitiremos a noção de RHS, descrita como conjunto de agentes capazes de desenvolverem ações de saúde, sejam as de promoção, proteção, recuperação ou reabilitação. Estes envolvem os profissionais, os técnicos e o pessoal de nível médio e elementar, inclusive os agentes comunitários, habilitados ou informais ${ }^{5}$.

\section{Desafios da regulação da formação} e da prática profissional no SUS

No Brasil, o mercado de trabal ho em saúdeapresenta características próprias, informadas pela dinâmica da reforma do setor, seja pelos investimentos decorrentes da política pública setorial, seja em função do desenvolvimento do mercado de planos e seguros de saúde.

Considerando o fator emprego, houve expansão da oferta de emprego público e privado, durante a década de noventa. Essa expansão foi impulsionada por variáveis como o processo de descentralização da atenção ambulatorial para o âmbito municipal e o crescimento do setor contratado do SU S e dos serviços médicos de planos e seguros de saúde.

No Brasil, o mercado de trabal ho formal do setor saúde absorve 2,15 milhões de empregos, 0 que representa quase $9 \%$ dos postos de trabal ho na economia formal. Os empregados em profissões eocupações de saúde somam $47 \%$ deste contingente ${ }^{6}$.

Este dinamismo está condicionado pelo processo maisgeral deajustemacroeconômico, marcado por uma tendência à precarização das relações detrabal ho eflexibilização nas condições de 
remuneração, adotada, sobretudo, entre gestores municipais e, entre estes, principalmente nas iniciativas referentes à expansão do Programa de Saúde da Família e de Agentes Comunitários. Considerando o setor privado, há evidências de redução na oferta de leitos disponíveis, que passou de 409.227, em 1992, para 341.871, em 1999, não obstante a elevação da oferta de empregos neste segmento $0^{5,7}$.

As mudanças promovidas no mercado de RHS levam a um maior direcionamento do foco dos estudos sobre força de trabal ho desenvolvidos a partir dos anos noventa, para o tema da crescente informalidade do trabalho, os quais sugerem estar o SUS seguindo a tendência geral da desregulação das relações de trabal ho ${ }^{8}$.

No processo de construção da política de RH para o SUS, além dos condicionantes macroeconômicos, estão implicados dois sistemas: 0 da formação/preparação para o trabalho e o da gestão do trabalho, que mantêm áreas de interseção com o subsistema de regulação das profissões. As competências estabel ecidas para gestão desses sistemas se encontram sob domínio de outros atores/instituições, que atuam em áreas que vão desde a formação/aperfeiçoamento profissional ao controle ético sobre atuação e ao controle sobre os locais de exercício da atividade.

As relações com a temática de recursos humanos em saúde envolvem sistemas de formulação de políticas com autonomia, direção e centralização próprias, não reguladas pela política do setor, mas diretamente afetadas pela regulação estatal diversificada para a área de relações humanas ${ }^{6}$.

Neste sentido, a capacidade do SUS em promover a regulação dos RH para o sistema, a despeito do respaldo jurídico-normativo, éinsuficiente. Há que se fazer, na perspectiva do ordenamento da formação de pessoal adequada às ne cessidades do sistema, investimentos que vão da reorganização dos serviços e práticas de trabaIho na assistência às mudanças curriculares, incluindo as mudanças nas práticas de ensino e preparação de docentes, além de uma definição mais clara quanto às diretrizes que informam a construção da política de RHS, considerando a tensão permanente entre os propósitos do SUSe as demandas de mercado ${ }^{5,9}$.

Oslimites epossibilidades do sistema em exercer essa capacidade regulatória devem ser analisados nos marcos do contexto dos processos de reforma do Estado e do setor, implementadas em vários países durante os anos oitenta e noventa, principalmente em sua orientação para a redução do Estado, com o consequente desmonte de suas estruturas burocráticas.

Esta perspectiva busca reduzir o papel da burocracia a uma forma específica de administração pública, defasada em relação ao estágio atual do processo de acumulação capitalista, desconsiderando que human resource management is a political function for regulation within and outside the public agencies, which mediates between a bureaucracy and ethical and political aims embodied in its institutional mission ${ }^{10}$.

Os movimentos deajuste macroeconômico e reforma no setor saúde têm pelo menos três grandes elementos de convergência: 0 apelo aos mercados, 0 apelo à eficiência e 0 apelo à flexibilidade. As estratégias de descentralização, com base nestes elementos, fazem surgir a possibilidade de novas formas de articulação entre o público e 0 privado, entreelas, a terceirização, a publicização e a del egação, com a emergência de novas formas de contratualização. A necessidade de construir capacidade no campo da gestão da relação de trabal ho e da regulação do exercício profissional passou a se constituir como uma decorrência dessas mudanças ${ }^{11}$.

A flexibilização das relações de trabalho, informada por novos modelos de relação públicoprivado no setor saúde, tem apontado para novas possibilidades de desenhos jurídico-normativos de estruturação de unidades prestadoras de serviços de saúde, onde se incluem as organizações sociais de saúde (OSS). A diversidade de formas de gestão/gerência de serviços de saúde implica a existência de novas modalidades de contratação, agregando complexidade ao processo de formulação de políticas de RHS.

Atualmente, é possível identificar como modalidades de vínculo predominantes no interior do sistema, as seguintes: (1) regimejurídico único - rege servidores públicos estatutários; (2) CLT - rege trabalhadores contratados sob o regime da Consolidação das Leis do Trabalho; (3) contratação comissionada - para preenchimento de cargos de livre provimento; (4) terçamento - vínculo de grupos profissionais, empresas ou outros órgãos e (5) contratação individual para prestação temporária de serviços. Estas modalidades admitem formas diferenciadas de sel eção, remuneração, progressão funcional, bem como de acesso a direitos trabalhistas, algumas delas marcadas por alto grau de informalidade equestionável base legal para sua contratação ${ }^{6}$.

A capacidade de gestão da relação de trabaIho, em qualquer âmbito do SUS, encontra-se bloqueada, seja pelos limites impostos aos ges- 
tores do sistema de saúde em decidir sobre a implementação da legislação trabal hista e sobre a política de formação de pessoal, seja pela pe quena autonomia conferida à gerência dos serviços de saúde.

Os gerentes dos serviços de saúde - especialmente os do setor público - são reféns de regulamentações que restringem severamente, no plano formal, sua autonomia para a contratação, descontratação e a negociação local dos termos dos contratos de trabalho (tendo em vista, por exemplo, a flexibilização das remunerações ou 0 estabelecimento demecanismos deincentivo/sanção condicionadas a metas qualitativas ou quantitativas) ${ }^{11}$.

O desafio de promover a adequação de RHS às necessidades de reorganização dos serviços, na lógica proposta pelo SUS, impõe a necessidade de um amplo processo de articulação e negociação entre os níveis de gestão do sistema de saúde e os tomadores de decisão em outras estruturas com poder deregulamentação sobre exercício da atividade profissional e sobre os conhecimentos e habilidades requeridas para o seu desempenho. 0 controle sobre estas atribuições encontra-se disperso entre diversas instituições, como o M inisté rio do Trabalho e Emprego, organizações de registro e controle profissional (CRM, COREN, CRP, etc.) e instituições formadoras (universidades, faculdades, escolas técnicas, etc.).

A peculiar vulnerabilidade das organizaçõese serviços de saúde às chamadas normas profissionais (frequentemente em conflito com as normas burocráticas e gerenciais e em detrimento destas) condiciona qualquer estratégia de contenção de custos ou melhoria da eficiência e da qualidade e acessibilidade dos serviços à capacidade de influir sobre os sistemas de autorização e controle profissionais. No atual sistema, é baixa essa capacidade de "governança profissional" pela gestão pública do setor, especialmente no que se refere às questões do direito e autorização de prática ${ }^{11}$.

O M inistério da Saúde, coordenador nacional do sistema, vem desenvolvendo uma série de estratégias no sentido de adequar o perfil de formação profissional às necessidades de desenvolvimento do SUS. Atualmente, parte significativa deste esforço vem sendo feita na reestruturação dos currículos na área, incluindo novas práticas pedagógicas. A institucionalização deste processo de alinhamento entre formação e organização deserviços, entretanto, limita-sea iniciativas pontuais, como exigir como requisito para habilitação de novas escolas médicas a adoção de meto- dologias ativas de aprendizagem (ênfase em ensino baseado em problemas) e novos arranjos institucionais para incorporar iniciativas de mudanças curriculares, desenvolvidos dentro ao longo das experiências de integração ensino-serviço, em suas diversas abordagens e desdobramentos.

0 investimento na formação/preparação de pessoal para o sistema deverá estar orientado pelo conceito de educação permanente, que contempla a necessidade dearticular mudanças curriculares, desenvolvimento de novos cenários de ensino, desenvolvimento dos processos de trabaIho e controle público.

A educação permanente parte do pressuposto da aprendizagem significativa (quepromovee produz sentidos) e propõe que a transformação das práticas profissionais deva estar baseada na reflexão crítica sobre as práticas reais em ação na rede de serviços. Propõe-se, portanto, que os processos de capacitação do pessoal da saúde sejam estruturados a partir da problematização do seu processo de trabalho eque tenham como objetivo a transformação das práticas profissionais e da própria organização do trabalho, tomando como referência as necessidades de saúde das pessoas e das populações, da gestão setorial e do controle social em saúde ${ }^{12}$.

Para construir viabilidade para operar sob esteconceito, éfundamental a integração dos diversos atores, que compartilham responsabilidades sobre a formação de pessoal, tais como instituições formadoras, gestores do SUS, organismos de controledo exercício profissional, tendo como objetivo o desenvolvimento de capacidades institucionais e pessoais que o sistema reclama para o seu fortalecimento.

A articulação desses atores einstituições deve, portanto, apontar para a necessidade de integrar conteúdos e práticas deformação/capacitação de pessoal à melhoria dos processos de trabalho, tendo como elementos direcionais a capacidade de resposta do sistema, dos serviços e ações de saúde às necessidades da população usuária e a melhoria dos indicadores pactuados entre os diversos níveis de gestão do sistema e as gerências dos serviços.

\section{Gestão do trabal ho e eficiência na administração direta enas organizações sociais desaúde}

No âmbito dos modelos de gestão adotados no setor saúde em São Paulo (organizações sociais e administração direta), as formas de ordenamen- 
to jurídico apresentam desdobramentos em re lação aos limites e possibilidades quanto à gestão do trabal ho em suas diversas dimensões - recrutamento, seleção, contratação, administração e controle, progressão funcional, entre outras que impactam sobre a utilização da capacidade instalada de RH.

No âmbito da gerência dos hospitais que ope ram sob o modelo de administração direta, predomina uma situação de baixa autonomia em relação ao controle sobre os RHS, que combina limites na capacidade deregulação do sistema, controle de gastos com pessoal decorrente da observância da Lei de Responsabilidade Fiscal e uma gestão centralizada de vários elementos que compõem a política de RH (recrutamento, seleção, incentivosao desempenho, sanções administrativas).

$N$ as unidades da administração direta (AD), os limites institucionais para implantação e implementação da política de RH estão relacionados ao condicionamento estabelecido por instrumentos que regulam os gastos públicos, que incluem tetos para gastos com pessoal, além de uma legislação que define a forma de ingresso e permanência no serviço público. Predomina nestas organizações a forma de seleção por meio de concurso público, que abrange $80 \%$ dos profissionais da unidade investigada. Esta forma de contratação, entretanto, depende de autorização da área econômica, que observa, além dos limites legais para gasto com pessoal, critérios próprios para alocação de recursos que nem sempre levam em consideração a relevância do setor saúde para o desenvolvimento de um país, estado ou região, mas apenas os gastos envolvidos com a oferta de serviços.

0 processo de alocação de pessoal nos HAD segue parâmetros técnicos baseados na relação profissionais/capacidadeinstalada (profissionais/ leito), definindo os quantitativos que vão compor 0 quadro de lotação das unidades assistenciais. A lógica tecnocrática não incorpora, entre tanto, a projeção sobre mudanças no perfil de mográfico e epidemiológico das regiões onde estas estão inseridas.

A inexistência de mecanismos que permitam às unidades desenvolverem capacidade adaptativa às mudanças no perfil sociodemográfico e sanitário das populações usuárias de seus serviços, por intermédio de um maior grau de autonomia para a provisão de suas necessidades de $\mathrm{RH}$, enseja a adoção de medidas administrativas para contratação de pessoal que apontam para a precarização das relações de trabalho, por meio de contratos temporários que não observam di- reitos trabalhistas básicos, como pagamento de férias, 13으, licença gestante, entre outros.

No caso do HAD investigado, o seu quadro de pessoal era o mesmo adotado em sua implantação há quinze anos. A criação de novos serviços demandou a necessidade de contratação de profissionais, que por não fazerem parte deste quadro, passaram a ser contratados de forma precarizada (contratos de prestação de serviço por período de tempo determinado e sem garantia de nenhum direito trabalhista), situação que abrangia cerca de $20 \%$ dos profissionais desta unidade. Este cenário não apenas contradita o que preconiza a legislação, como coloca, neste caso, a administração direta em situação de desvantagem competitiva frente às organizações sociais.

As limitações quanto ao gerenciamento das relações de trabal ho, no âmbito das unidades da administração direta, são evidenciadas, ainda, nos aspectos relativos ao controle sobre os processos de descontratação, bem como ao da progressão funcional, com implicações sobre os níveis de eficiência destas organizações, considerando a forma burocratizada como estas questões são tratadas.

Em relação ao acesso às vagas, no âmbito do HOSS, o processo seletivo está orientado por uma segmentação deresponsabilidades, quanto à contratação, em três grandes setores: médico, de enfermagem e administrativo. Os dois primeiros são responsáveis pela seleção de seus pares, os demais são selecionados pelo setor de administração de pessoal. 0 ingresso é mediante processo sel etivo, ancorado, princi palmente, em análise de currículo e entrevistas para identificação do perfil do candidato.

Esta segmentação se desdobra em outros campos deatividade referentes à área de $\mathrm{RH}$, com pouca integração earticulações internas, capazes de traduzir um projeto de política de RH em suas várias dimensões, além de traduzir deforma bastante evidenteas relações de poder entreas diversas profissões da área de saúde e destas com as profissões do setor administrativo.

Todos os admitidos na organização têm seus vínculos de trabalho ordenados segundo a Consolidação das Leis do Trabalho (CLT), mesmo os contratados por tempo determinado para substituição deférias ou licenças. A definição sobre formas de contratação de pessoal, sob qualquer forma de vínculo, é de decisão exclusiva da OSS, respeitado o limite orçamentário para gasto com pessoal, queé de $70 \% 13,14$.

Tendo em vista a inexistência de um plano de cargos, salários e carreira, a perspectiva de pro- 
gressão funcional éimplementada com um forte componentede informalidade, com base na avaliação do desempenho do funcionário realizada pelas chefias imediatas. Esta falta de perspectiva de progressão funcional estabelecida em instrumentos próprios de gestão das relações de trabaIho tem desdobramentos sobre outra importante variável na organização do trabalho, que são os índices de rotatividade.

Entre os indicadores utilizados para avaliação de produtividade de unidades hospitalares, um dos mais empregados refere-seà relação funcionário/leito. Não obstante à tendência à diminuição do número deleitos hospitalares, seja pela transferência de vários procedimentos para a rede ambulatorial, pelo estímulo à desospitalização de alguns problemas de saúde (destaque para saúde mental) ou mesmo pela instituição de serviços de home-care, os dados disponíveis sobre este indicador demonstram um aumento desta relação, influenciado pelo processo de incorporação tecnológica observada para o setor saúde.

Trabal ho desenvolvido sobre a situação deste indicador para um conjunto de hospitais públicos e privados no município de São Paulo encontrou uma relação que variou de 5,1 a 13,615. O bservando a evolução deste indicador, também para um conjunto de municípios de São Paulo, foi detectado que esta relação passou de 3,2 (1977) para 5,8 (1988), chegando, em 1994, a 7,16,17.
O Quadro 1 apresenta a situação das unidades hospitalares investigadas, segundo alguns indicadores relativos à eficiência dos serviços. Os indicadores apontam para uma melhor relação funcionário/leito por parte da OSS. As taxas médias de permanência (TMP) apresentam resultados muito próximos para os anos comparados. Este resultado, referente à $\mathrm{TM} P$, indica a presença de critérios técnicos compartilhados para conduta em relação à alta, pertinenteao tipo de burocracia que caracteriza organizações hospitalares - as ditas profissionais.

A taxa média de ocupação apresenta convergência em relação aos resultados para 0 ano de 2002. Entretanto, o valor médio para os anos comparados revela uma diferença em favor da OSS ( $85 \%$ ), em relação à unidadeda AD $(79,5 \%)$. A meta estabelecida para as OSS, para o ano de 2001, era de uma TM O de 75\%, segundo o contrato de gestão $0^{4}$. 0 acompanhamento dos resultados tem permitido a negociação do ajuste das metas entre os contratantes.

Esta diferençano desempenho se expressa em outros dados referentes à produção comparada destas duas unidades, considerando um conjunto de procedimentos, bem como a relação profissional/leito, tomando como base as categorias médica e de enfermagem ( $Q$ uadro 2).

Os dados relativos à produção de procedimentos, considerando aqueles aqui comparados,

Quadro 1. Hospitais segundo alguns indicadores de eficiência (2001/2002/2003).

\begin{tabular}{|l|c|c|c|c|c|c|c|c|c|}
\hline \multirow{2}{*}{ H ospitais } & \multicolumn{3}{|c|}{2001} & \multicolumn{3}{|c|}{2002} & \multicolumn{3}{c|}{2003} \\
\cline { 2 - 10 } & Func./leito & TM O & TM P & Func./leito & TM O & TM P & Func./leito & TM O & TM P \\
\hline H AD & 7,1 & $81,5 \%$ & 5 & 6,8 & $79,5 \%$ & 5,0 & 6,4 & $77,6 \%$ & 5,1 \\
\hline HOSS & 3,9 & $88,7 \%$ & 4,8 & 3,8 & $80,3 \%$ & 5,05 & 4,1 & $86,1 \%$ & 5,02 \\
\hline
\end{tabular}

Fonte: Relatórios de atividades - H GVP/H GIP.

TM O (taxa média de ocupação) - número de pacientes em determinado período/número de leitos-dia no mesmo período x 100 TM P (taxa média de permanência) - número de pacientes em determinado período/número de pacientes saídos no mesmo período ${ }^{18}$.

Quadro 2. Produção de procedimentos e relação profissional/leito por unidade hospitalar (2001/2002/2003).

\begin{tabular}{|l|c|c|c|c|c|c|c|c|c|c|c|c|}
\hline & \multicolumn{4}{|c|}{ Partos } & \multicolumn{3}{c|}{ Cirurgias } & \multicolumn{3}{c|}{ Enfermeiro/leito } & \multicolumn{3}{c|}{ M édico/leito } \\
\cline { 2 - 14 } H ospitais & 2001 & 2002 & 2003 & 2001 & 2002 & 2003 & 2001 & 2002 & 2003 & 2001 & 2002 & 2003 \\
\hline HAD & 3.221 & 3.297 & 2.593 & 3.306 & 3.177 & 3.476 & 0,29 & 0,29 & 0,32 & 1,54 & 1,53 & 1,46 \\
\hline HOSS & 5.383 & 5.635 & 5.235 & 5.208 & 5.025 & 5.984 & 0,19 & 0,21 & 0,23 & 0,89 & 0,88 & 0,97 \\
\hline
\end{tabular}

Fonte: Relatório de Atividades- HAD / HOSS. 
apontam para um ganho deeficiência da OSfrente à unidade sob administração direta. Essa vantagem competitiva pode ser confirmada quando se comparam os números de produção com indicadores referentes à relação enfermeiro/leito e médico/leito, que demonstram uma melhor relação destes indicadores na OS. Considerando que, para o período acima (2001/2002/2003), as referidas unidades hospitalares apresentavam, segundo relatório de atividades, uma oferta de leitos correspondentea 184/192/202 (HAD) e249/ 264 (H OSS), é possível inferir uma vantagem competitiva da OSS frente ao hospital da administração direta.

Esta relação profissional/leito revelauma tendência de aumento nas duas categorias comparadas (médicos e enfermeiras), consistente com um movimento de expansão de serviços. Por outro lado, esta relação na unidade da AD apre senta uma discreta diminuição, indicativa de uma dificuldade de ampliar a oferta de novos serviços, uma vez que não há nenhuma referência quanto à implementação de medidas racionalizadoras quanto à distribuição de profissionais.

Os dados indicam uma melhor utilização da capacidade instalada de RH por parte da OSS; esta melhor relação pode ser explicada pelo limite de gasto em RHS imposto pelo contrato de gestão, aliado à necessidade de alcançar as metas estabelecidas neste contrato, dentro dos limites orçamentários definidos. As discretas tendências de aumento nesta proporção (funcionário/leito) na OSS ediminuição na AD estão referidas à crescente ampliação da oferta de serviços desde a abertura da unidade (1998), em relação à primeira, eà dificuldade para contratação de pessoal para suprir necessidades (inclusive de expansão de serviços), no caso da segunda.

\section{Rotatividades e remuneração nas experiências da AD eOSS}

A adoção de mecanismos de mercado para contratação de pessoal pode assegurar um processo de reposição de necessidades mais ágil e mais aderido àsnecessidades da população usuária dos serviços, com possibilidades de melhor utilização da capaci dadeinstalada física e de RH. Entretanto, o apelo ao mercado tende à conformação de uma maior instabilidade no quadro funcional, caracterizada por al tos índices de rotatividade, contrariando a expectativa de que contratação com salários acima da média paga pela administração direta (dado que não se confirma para todas as categorias) venha a ser fator de manutenção de contratados em áreas distantes.

A alta rotatividade de pessoal, no caso da OS estudada, pode ser atribuída à localização desta e aos problemas decorrentes de acesso a outros pontos da cidade, que devem influenciar no exercício demúltiplos vínculos detrabal ho comunsentreas duas categorias representadas no Quadro 3. Esta avaliação deve ser comparada com a situação de outras OSS localizadas em pontos mais centrais da cidade para que possa ser corroborada.

Em relação à unidade da administração direta, épreciso considerar que as condições de acesso ao cargo, que na maioria dos casos se faz mediante concurso público, aliadas à maior flexibilidade no exercício das atividades, deve influir na sua baixa rotatividade, comparativamente à OS. Um estudo mais detalhado sobre os motivos de recusa à participação em concursos públicos por certas especialidades, bem como sobre os motivos de pedidos de exoneração, podem informar mais sobre as razões desta baixa rotatividade naAD.

0 efeito de um al to índice de rotatividadeestá relacionado ao risco de solução de continuidade no desenvolvimento das atividades, à sobrecarga de trabalho aos que se mantêm na unidade até a substituição e adaptação funcional dos novos contratados, ou mesmo quanto as suas repercussões sobre projetos de desenvolvimento institucional, que dependam da expertise dos egressos da organização.

Uma das premissas para construção do SUS era a de que a unificação do sistema implicaria tratamento igualitário aos trabalhadores do setor

Quadro 3. Índice de rotatividade por categoria e hospital (2002/2003, período de janeiro a julho).

\begin{tabular}{|l|c|c|c|c|}
\hline \multirow{2}{*}{ Categoria } & \multicolumn{2}{|c|}{ HAD } & \multicolumn{2}{c|}{ HOSS } \\
\cline { 2 - 5 } & 2002 & 2003 & 2002 & 2003 \\
\hline M édico & $1,2 \%$ & $0,6 \%$ & $19,22 \%$ & $12,18 \%$ \\
\hline Enfermagem & $2,0 \%$ & $5,9 \%$ & $16,8 \%$ & $11,09 \%$ \\
\hline Geral & $1,3 \%$ & $2,2 \%$ & $19,38 \%$ & $12,46 \%$ \\
\hline
\end{tabular}

Fonte: Coordenação deRH - HAD/HOSS.

Índice de rotatividade: medea relação entre entrada e saídas de funcionários, segundo o período avaliado. Expresso sob a forma de percentual, com baseno cálculo: média entre admissões e demissões, dividida pela média de funcionários em um determinado período, multiplicado por $100^{18}$. 
público, independente do nível de gestão a que estivessem vinculados. A pontava para o processo deestruturação deplanos decargosecarreira como estratégia privilegiada. A descentralização de recursos e atribuições entre os gestores do sistema dificultou o desenvolvimento desta estratégia. Não apenas foi impossível até o momento promover isonomia salarial no setor, como a adoção de novos arranjos institucionais na relação público versus privado instituiu outras modalidades de contratação de pessoal com diferentes formas e valores de remuneração. $N a A D$, prevalece a admissão por concurso público, regido por estatutos.

Os níveis de remuneração praticados na $A D$ são considerados como defasados, quando comparados àqueles praticados no setor privado, considerando a remuneração da categoria médica como base de comparação.

O salário-base pago pela Secretaria de Estado de São Paulo, em 2001, para vinte horas semanais, era de $R \$ 1.253,00$. Esses valores estão aquém da média de salário do Estado ( $R \$$ $2.585,79)$ e da recomendação da Confederação $\mathrm{N}$ acional dos M édicos (R\$2.500,00) .

As médias salariais praticadas pelas duas unidades públicas (OSS eAD) são inferiores àquelas praticadas pelo mercado entre a categoria médica, com uma diferença em torno de 7,9\% frenteà OS e de aproximadamente $9 \%$ em relação à unidade da administração direta. Em relação às enfermeiras, a diferença, comparativamenteaos valores praticados pelo mercado, apresenta uma vantagem de 4,9\% em favor da OS e uma defasagem de $26,5 \%$ em relação à unidade da AD. Em relação às auxiliares de enfermagem, a diferença entre os valores de mercado e OS chega a $7 \%$ em favor da OS e apresenta uma pequena defasagem de 3,3\% frente à unidade da administração direta (Quadro 4).
Essa comparação, quando realizada entre a unidade no modelo OS e da administração direta, apresenta a seguintesituação: em relação à categoria médica, há uma diferença em favor da unidade da OS em torno de 1,4\%\%; esta situação se mantém em relação às enfermeiras, com umadiferença de $30 \%$ em favor da OS; entre as auxiliares de enfermagem, a vantagem da OS frente à unidadedaAD éde $9,7 \%$. A comparação feita entrea unidade sob gestão direta com a OS e os valores de mercado levou em consideração a carga horária contratual entre a primeira e as demais.

Importante ressaltar o fato de que os valores praticados pela unidade sob gestão direta são inferiores aos valores de mercado. Este fato caracteriza a desvalorização dos RH S e está no centro do constante processo de migração da mão de obra com melhor nível de qualificação em direção ao mercado. A pesar da autonomia concedidaàs OSS, a inexistência deuma política de RH que inclua perspectiva progressão funcional para todas as categorias, bem como remuneração mais próxima aos valores de mercado para a categoria médica, poderá estar influindo sobre os índices de rotatividade observados nesta unidade.

Tomando como referência a remuneração média praticada pelo mercado, pode ser observada uma discrepância entre a remuneração oferecida pelo setor público e o nível de qualificação das categorias profissionais comparadas. A distribuição dos valores praticados pela $A D$, segundo nível de aproximação com o mercado, apresenta a seguinte ordem: auxiliares de enfermagem, médicos e enfermeiras. Em relação à OSS, é possível observar a seguinte ordem de importância: auxiliares de enfermagem, enfermeiras e médicos. N este caso (da OSS), há uma clara opção por um investimento maior junto aos profissionais envolvidos com a prestação do cuidado direto e continuado ao usuário.

Quadro 4. M édias salariais por categoria e hospital (2003).

\begin{tabular}{|l|c|c|c|}
\hline \multicolumn{1}{|c|}{ Categoria } & HAD* & HOSS* & M ercado** \\
\hline M édico & $\mathrm{R} \$ 2.393,16(100 \mathrm{~h})$ & $\mathrm{R} \$ 2.909,47(120 \mathrm{~h})$ & $\mathrm{R} \$ 3.156,00(120 \mathrm{~h})$ \\
$(91 \%)$ & $(92,1 \%)$ & $(100 \%)$ \\
\hline Enfermeira & $\mathrm{R} \$ \begin{array}{c}1.655,12(150 \mathrm{~h}) \\
(73,5 \%)\end{array}$ & $\begin{array}{c}\mathrm{R} \$ 2.835,69(180 \mathrm{~h}) \\
(104.9 \%)\end{array}$ & $\begin{array}{c}\mathrm{R} \$ 2.702,00(180 \mathrm{~h}) \\
(100 \%)\end{array}$ \\
\hline Auxiliar de enfermagem & $\mathrm{R} \$ \begin{array}{c}1.056,09(150 \mathrm{~h}) \\
(96,7 \%)\end{array}$ & $\mathrm{R} \$ 1.403,35(180 \mathrm{~h})$ & $\mathrm{R} \$ 1.311,00(180 \mathrm{~h})$ \\
& $(107 \%)$ & $(100 \%)$ \\
\hline
\end{tabular}

Fontes: *Coordenação de RH - HOSS/H AD; ** SES-SP/Coordenação deContrato de Serviços de Saúde (CCSS)/D epartamento deGestão eControle de Contratos (DGCC). 
As dificuldades para enfrentar o problema do ordenamento das relações de trabalho, em especial quanto aos níveis de remuneração, abre espaço para a adoção de medidas que objetivam compensar defasagens entre valores praticados entre o setor público e o mercado, como a instituições de gratificação de diversos tipos (por assiduidade, produtividade, locomoção até o local de trabalho), que devem ser subtraídas do cálculo do benefício da aposentadoria.

A SES-SP instituiu, no âmbito das unidades daAD, a incorporação de uma gratificação, como forma de incentivo ao desempenho, que na prática funciona como complementação salarial, na medida em que não foram estabelecidos mecanismos e instrumentos de avaliação de desempenho individual ou setorial que servissem de parâmetros para o pagamento desta gratificação, ou seja, não estão vinculados a critérios de eficiência a serem atingidos.

A lógica em que estão baseadas as diferentes remunerações praticadas pelas duas unidades está inserida em uma perspectiva mais abrangente, que considera a possibilidade de, dentro dos marcos do processo de descentralização instituído pela delegação de responsabilidades do setor público ao setor privado, promover melhora nos níveis de eficiência das organizações públicas. Tal premissa inclui o gerenciamento de RH em sentido amplo, bem como deaquisição de benseserviços, etem antecedentes em um conjunto de iniciativas desenvolvidas na administração pública, que busca combinar melhoria da eficiência na produção de bens e serviços públicos com descentralização.

A instituição denovosarranjos institucionais na relação público versus privado no setor saúde, em especial da figura jurídica emergente nesta relação - as organizações sociais de saúde - coloca para o SUS o desafio de criar formas de ordenamento das relações de trabalho que comportea diversidade de formas de seleção, contratação, vínculo e remuneração que esta modalidade de gestão agrega às já existentes, que afasta, cada vez mais, a aplicação de mecanismos deisonomia entre os profissionais do setor.

\section{Consideraçõesfinais}

A reforma gerencial, implantada em 1995, tem como objetivos declarados melhorar a eficiência do Estado e a qualidade no serviço público. Inspirada em princípios da administração privada, busca promover autonomia e a responsabilização e accountability das agências públicas, como estratégia para eficiência e qualidade 3 .
As organizações sociais de saúde representam a possibilidade de, nos marcos da proposta dessa reforma administrativa, constituírem-se como alternativa aos problemas de desempenho do modelo burocrático. Sua característica fundamental está na capacidade de gerar um maior nível de autonomia gerencial aos diretores de unidades sob este modelo de gestão, considerando a compra de bens e serviços e a provisão de RH.

Esta autonomia tem como contrapartida a flexibilização nas relações de trabal ho no âmbito do setor saúde, com impacto positivo (pelo menos no caso das OSS habilitadas pela Secretaria de Estado da Saúde de São Paulo) sobre indicadores de produtividade. Esta articulação entre modelos descentralizados de gestão e eficiência reclama novas formas de regulação das relações de trabalho que incluam a presença de novos agentes, decorrentes do processo de publicização proposta na reforma gerencial (1995).

Importante ressaltar que regras para flexibilização das relações de trabal ho na administração pública já encontram respaldo na legislação (Emenda Constitucional $n^{\circ} 19$ ), podendo ser adotadas também para AD. 0 espaço para uma maior apropriação da experiência proporcionada pelas OSS tem condicionantes de ordem legal, que envolvem a própria existência destas figuras jurídicas e formas cristalizadas de relações de trabaIho naAD, com fortesubstrato cultural eideológico resistente a mudanças na forma prevalente de gestão das relações de trabalho no setor público.

As vantagens competitivas observadas pelo modelo OSS decorrem de uma maior autonomia na contratação de seus recursos humanos e em sua capacidade de usar esta autonomia para promover rápida reposição de pessoal e explorar, com base nesta autonomia, uma maior capacidade de utilização destes recursos, uso este condicionado pel os compromissos estabelecidos nos contratos de gestão, quefixam metas de produção e de produtividade a estas unidades.

0 aprendizado proporcionado pelo modelo OSS tende a ser incorporado às unidades da AD em diversos aspectos, sobretudo quanto aos níveis de eficiência por elas alcançados (comparativamente às da AD). Entretanto, dois grandes desafios se colocam nesta empreitada: superar a tendência à manutenção do debate sobre aspectos ideológicos, marcado pelo discurso referente ao risco de privatização e contornar os limites impostos pela legislação trabalhista aplicada ao setor público e pela influência corporativista no setor, sobretudo de corporações com forte hegemonia setorial e influência social. 


\section{Referências}

1. Arruda DMC, Mandelli MJ. Autonomia administrativa em saúde: subsídios para discussão. Rio de Janeiro: IM S-UERJ; 1993. [Série Estudos em saúde Coletiva no 58]

2. Vaz JC. As Organizações Sociais no contexto da Reforma do Estado. In: Capucci PF, Diogo A, organizadores. Organizações sociais: público e privado na saúde. São Paulo: APSP; 1999. p. 10-18.

3. Bresser Pereira LC. Reforma da nova gestão pública: agora na agenda da América Latina, no entanto... Revista do Serviço Público 2002; 53(1):5-27.

4. I bañez N, Bittar OJNV, Sá ENC, Yamamoto EK, Almeida M F, Castro CGJ. Organizações sociais de saúde: o modelo do Estado de São Paulo. Cien Saude Colet 2001; 6(2):391-404.

5. Paim JS. Recursos humanos em Saúde: problemas crônicos e desafios agudos. São Paulo: USP; 1994.

6. Pierantoni $C R$. Recursos humanos e gerência no SUS. In: Viana ALd'A, Negri B, organizadores. 0 Sistema Ú nico de Saúde em dez anos de desafio. São Paulo: Sobravime/Cealag; 2002. p. 609-630.

7. Costa NR, Silva PLB. Características do mercado de trabalho no setor saúde na década de 1990: reflexões. In: Negri B, Faria R, Viana ALd'A, organizadores. Recursos humanos em Saúde - política, desenvolvimento e mercado de trabalho. Campinas: $\mathrm{Nepp} /$ Unicamp; 2002. p. 275-286.

8. Nogueira RP. 0 trabalho em saúde hoje: novas formas de organização. In: Negri B, Faria R, Viana ALd'A, organizadores. Recursos humanos em Saúde - política, desenvolvimento e mercado de trabalho. Campinas: Nepp/Unicamp; 2002. p. 257-274.

9. Fonseca CD, Seixas PHD. Agenda nacional de Recursos Humanos em Saúde: diretrizes e prioridades. In: Negri B, Faria R, Viana ALd'A, organizadores. Recursos humanos em Saúde - política, desenvolvimento e mercado de trabalho. Campinas: Nepp/ Unicamp; 2002. p. 289-322.

10. Nogueira RP, Santana JRP. Human resource management and public sector reforms: trends and origins of a new approach [Texto para discussão $n$ ㅇ 888]. Brasília: IPEA; 2002.
11. Girardi S. A regulação dos recursos humanos em saúde e a reforma do setor saúde em países da América Latina. [site da Internet]. Disponível em: http://www. opas.org.br/rh/admin/documentos/ACF47.pdf

12. Brasil. Ministério da Saúde. Política de Educação Permanente para o SUS. Brasília: M inistério da Saúde; 2003.

13. São Paulo. Projeto de Lei Complementar no 3, de 17 de fevereiro de 1998. Dispõe sobre a qualificação de organizações sociais. Diário Oficial do Estado de São Paulo 1998; 19 fev.

14. São Paulo. Lei Complementar no 846, de 4 de junho de 1998. Dispõe sobre a qualificação de entidades como organizações sociais. In: Lex: coletânea de legislação e jurisprudência. Vol. 62. São Paulo: Lex Editora; 1998. p. 906-913.

15. Zucchi P. Funcionários por leito: estudo em alguns hospitais públicos e privados. Rev. Adm. Pública 1998; 32(3):65-76.

16. Bittar OJNV. Produtividade em hospitais de acordo com alguns indicadores hospitalares. Rev. Saude Publica 1996; 30(1):53-60.

17. Bittar OJNV. Distribuição de Recursos Humanos em oito hospitais gerais de São Paulo. Rev. Panam. Salud Públ. 1997; 2(31):37-43.

18. Unisinos. Sistema de Indicadores Padronizados para Gestão Hospitalar - SIPAGEH. [acessado 2004 ago]. Disponível em: http://www.economicas.unisinos.br/ sipageh/apres.php

Artigo apresentado em 25/10/2007

Aprovado em 27/06/2008

Versão final apresentada em 06/08/2008 